Keio J. Med. 29: 133-140, 1980

\title{
SYSTOLIC TIME INTERVALS IN INTRATRACHEAL CARDIOGRAM
}

\author{
MASAO NAGANO, HIROMASA SEKIGUCHI, TOSHIYUKI SHIGEMATSU \\ and MICHINOSUKE AMANO
}

Department of Anesthesiology, School of Medicine, Keio University, Tokyo, Japan

(Received for publication June 19, 1980)

\begin{abstract}
By means of a newly developed sensitive pressure transducer connected to the endotracheal tube of the anesthetized patient, small changes of air pressure through the airway caused by cardiogenic mechanical oscillations were recorded during apneic condition induced by succinylcholine chloride. This pressure recording was tentatively termed as an intratracheal cardiogram (ITCG).

This transducer has a high resonant frequency enough for precise recording of spike waves in ITCG caused by valvular movements.

Some of the parameters calculated from the spike waves in ITCG with reference to $\mathrm{ECG}$; i.e. $\mathrm{QC}, \mathrm{BC}, \mathrm{QB}$, and $\mathrm{QB} / \mathrm{BC}$, were compared with such indices of systolic time intervals (STI) simultaneously obtained by the conventional non-invasive methods as EMS, LVET, PEP, and PEP/LVET. There are highly significant correlations between the corresponding parameters and derivatives of the conventional and new methods. This technique is expected to be useful tool in assessing cardiac function during endotracheal intubation.
\end{abstract}

The measurement of systolic time intervals (STI) has recently been recognized to be useful as a non-invasive method for evaluating cardiac functions. The parameters of STI are usually obtained by means of a typical conventional method such as simultaneous recordings of ECG, phonocardiogram (PCG), and carotid arterial pulse (CAP). These procedures are in fact complicated and difficult to perform repeatedly during surgical operation. A better non-invasive method, therefore, is desirable.

Anesthesiologists may have occasionally noticed slight pulsatile movement 
of the anesthetic rebreathing bag caused by cardiogenic beat-to-beat movements during endotracheal anesthesia when the patients are apneic. This phenomenon has been known for several decades as pneumocardiogram and thought of as pulsatile gas movement in the airway caused by each cardiac cycle. ${ }^{1}$ We recorded this gas movement as pressure change using a highly sensitive pressure transducer. We have named this wave tentatively as an intratracheal cardiogram (ITCG).

In order to evaluate the ITCG in respect of reference to cardiac functions, analysis of the pattern of this wave was performed by comparing it with the conventional STI obtained simultaneously with the ordinary non-invasive method..$^{2-4}$

\section{MATERIALS AND METHODS}

Twenty nine patients, in ages ranging from 14 to 67 years with no detectable cardiopulmonary diseases, were studied before surgery. Premedication was consisted of pentobarbital $(100 \mathrm{mg})$, Pentazocine $(30 \mathrm{mg})$ and atropine sulfate $(0.5 \mathrm{mg})$. Anesthesia was induced with intravenous thiopental $(3-4 \mathrm{mg} / \mathrm{kg}$ ) and succinylcholine $(1 \mathrm{mg} / \mathrm{kg})$ injections followed by endotracheal intubation with Rusch cuffed tube, then anesthesia was maintained with halothane and nitrous oxide. When the patient's vital signs were stabilized, the endotracheal tube was connected to the transducer (PM-25, Nihon Koden Co.) to measure the pressure change in the airway, therefore the patients were made apneic for upmost only ten seconds, and so this procedure did not cause any harmful disturbance in respiratory performance. The intravenous fluid administration was kept in minimum dose during the study to avoid its undue influence.

The transducer which was constructed especially for this study has a natural resonant frequency of approximately $300 \mathrm{~Hz}$, and output voltage of $1 \mathrm{mV}$ for input pressure change of $1 \mathrm{~mm} \mathrm{H}_{2} \mathrm{O}$. Some problems about the practical use of this transducer will be mentioned later. The electrical output of the DC amplifier (RDG-5, Nihon Koden Co.) transmitted from the transducer was recorded on a multichannel UV recorder (Yokogawa Elect. Co.) at a paper speed of 100 or $200 \mathrm{~mm} / \mathrm{sec}$ with a time constant of $2.0,0.1$ and $0.01 \mathrm{sec}$.

The parameters of STI obtained by conventional method were as follows (dimension is $\mathrm{msec}$ ): (1) The total electromechanical systole (EMS) was measured from the onset of the QRS in the ECG to the first vibration of the second heart sound in the PCG. (2) The left ventricular ejection time (LVET) was measured from the onset of the upstroke to the dicrotic notch in the CAP. (3) The pre-ejection period (PEP) was obtained by subtracting the LVET from 
the EMS. The PEP/LVET was then calculated. ${ }^{5}$

The STI indices in ITCG were obtained by measureing the distance between the characteristic points of the wave and the ECG as described later. All intervals were calculated from the mean values obtained from ten consecutive beats. Reproducibility of every beat in the ITCG was ascertained by averaging ten consecutive wave patterns with the digital computer (ATAC-401. Nihon Koden Co.). The $R$ wave in the ECG was used as a trigger for each cardiac cycle. The STI parameters by the conventional method and indices by the ITCG were compared by analysis of variance. The level of significance for the regressions and for differences between the parameters and/or indices obtained by two methods was taken as $\mathrm{P}<0.05$.

\section{RESULTS}

Most frequently recorded pattern of ITCG is shown in Fig. 1. There are some characteristic points in ITCG shown in Fig. 2, and in the actual recording,

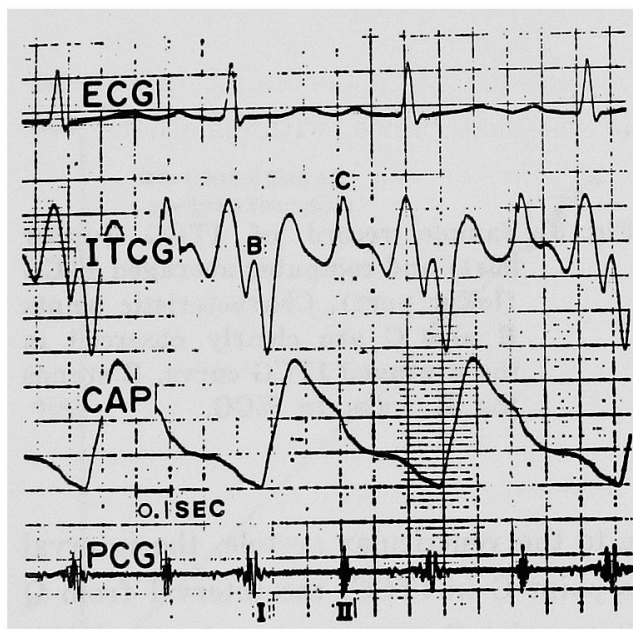

Fig. 1 Actual recording of ITCG with simultaneously recorded other circulatory measurements. B, C indicate characteristic points that appeared in ITCG. CAP = carotid arterial pulse. $\mathrm{PCG}=$ phonocardiogram.

Down-ward deflection by the negative pressure in ITCG. Maximum amplitude of ITCG is about $2 \mathrm{~mm} \mathrm{H}_{2} \mathrm{O}$.

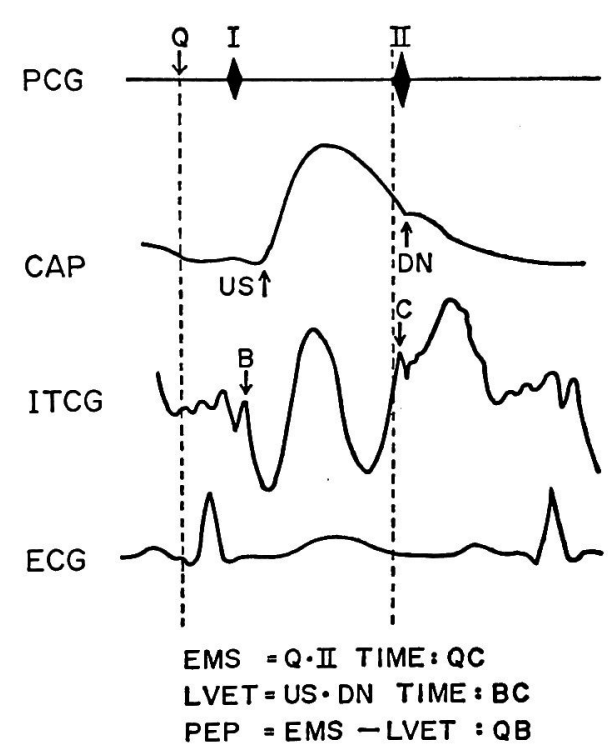

Fig. 2 Schematic drawing of ITCG showing points in relation to circulatory events recorded in other measurements. For more details, see text. US $=$ upstroke. $\mathrm{DN}=$ dicrotic notch. 
which were consistently detected in all records. The point $B$ is the first upward notch following $R$ wave in the ECG. The point $C$ is the first upward spike corresponding to the second heart sound in the PCG.

Every cycle of the ITCG were shown to be identical by averaging ten consecutive cardiac cycles with a computer, because point $\mathrm{B}$ and $\mathrm{C}$ were clearly recognized in the computed ITCG as seen in Fig. 3.

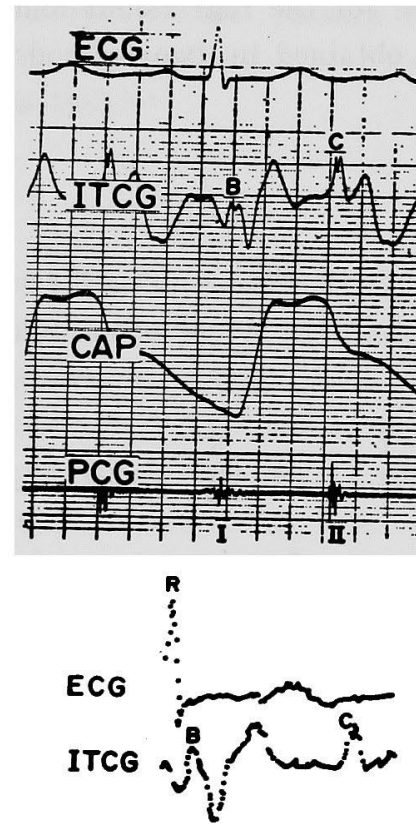

Fig. 3 Sample record of ITCG (upper part) and computer-averaged ITCG (lower part). Characteristic points $\mathrm{B}$ and $\mathrm{C}$ are clearly obserced in the averaged ITCG curve. $R$ stands for $R$ wave in ECG.

Assuming that these points correlate to the ventricular systole, the interval from the onset of the $Q$ wave on ECG to point $C$ in ITCG, the interval from $Q$ to point $B$, and the interval from point $B$ to point $C$ were compared with EMS, PEP and LVET respectively (Fig. 2). The time intervals in ITCG and simultaneously obtained conventional STI in twenty nine patients are summarized in Table 1. Mean time intervals of $\mathrm{QC}, \mathrm{BC}$ and $\mathrm{QB}$ were $443 \pm 23 \mathrm{msec}, 323 \pm 31$ msec and $120 \pm 28 \mathrm{msec}$ respectively. Corresponding EMS, LVET and PEP were $440 \pm 23 \mathrm{msec}, 332 \pm 29 \mathrm{msec}$ and $118 \pm 25 \mathrm{msec}$ respectively. The ratio of $\mathrm{QB}-\mathrm{BC}$ was $0.356 \pm 0.102$ and the ratio of $\mathrm{PEP} / \mathrm{LVET}$ was $0.373 \pm 0.108$. By comparing these corresponding data, there was no significant difference among them $(\mathrm{p}<0.001)$. 


\section{Table 1}

Comparison of systolic time intervals and their derivatives by conventional technique and intratracheal cardiogram (Mean $\pm 1 S D)$

\begin{tabular}{|c|c|c|c|c|c|c|c|}
\hline EMS & QC & LVET & $\mathrm{BC}$ & PEP & $\mathrm{QB}$ & PEP/LVET & $\mathrm{QB} / \mathrm{BC}$ \\
\hline \multicolumn{2}{|c|}{ (msec) } & \multicolumn{2}{|c|}{ (msec) } & \multicolumn{2}{|c|}{ (msec) } & & \\
\hline 440 & 443 & 322 & 323 & 118 & 120 & 0.373 & 0.356 \\
\hline 23 & 23 & 29 & 31 & 25 & 28 & 0.108 & 0.102 \\
\hline \multicolumn{2}{|c|}{$\mathrm{p}<0.001$} & \multicolumn{2}{|c|}{$\mathrm{p}<0.001$} & \multicolumn{2}{|c|}{$\mathrm{p}<0.001$} & \multicolumn{2}{|c|}{$\mathrm{p}<0.001$} \\
\hline
\end{tabular}

A highly significant linear relationship was found between the durations of the phases of ventricular systole in ITCG and the STI obtained by the conventional technique (Fig. 4, 5, 6). There was also a good correlation in the ratio of $\mathrm{PEP} / \mathrm{LVET}$ and the corresponding $\mathrm{QB} / \mathrm{BC}$ ratio (Fig. 7).

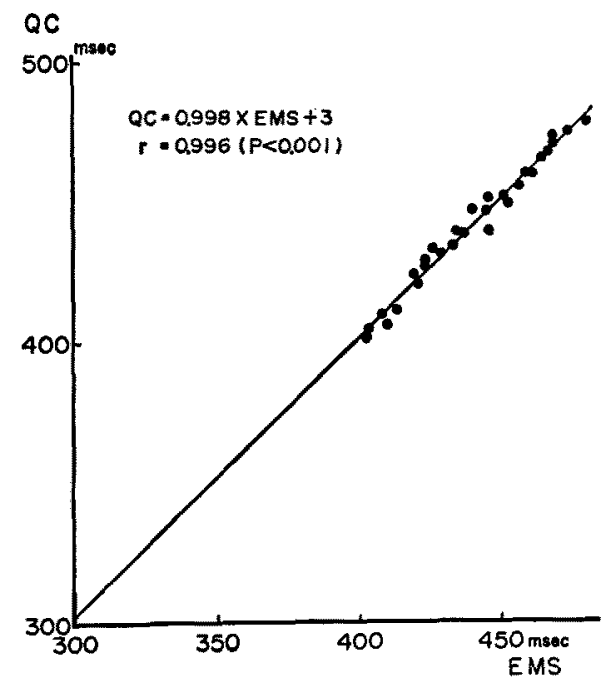

Fig. 4 Correlation between QC time in ITCG and electromechanical systole (EMS).

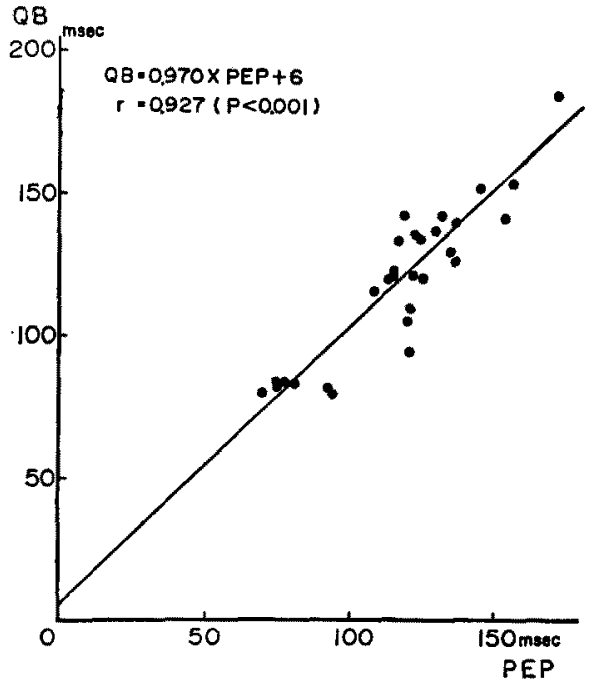

Fig. 5 Correlation between QB time in ITCG and preejection period (PEP). 

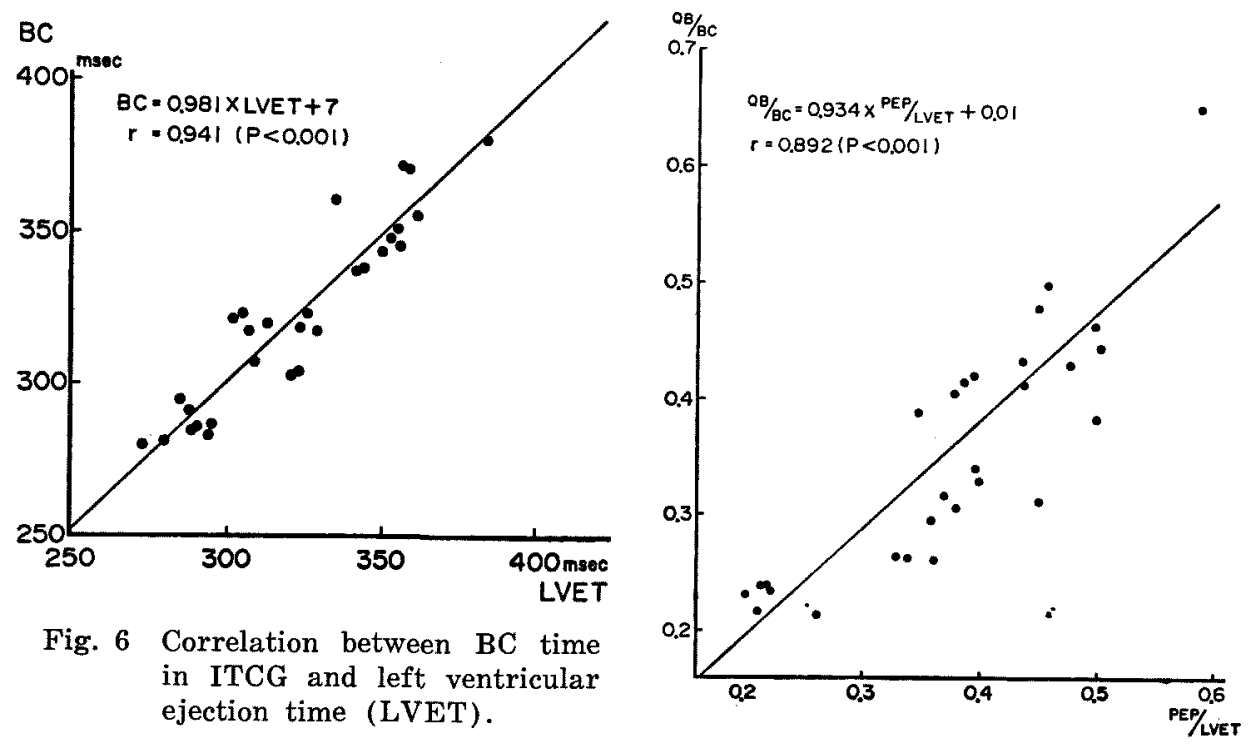

Fig. 7 Correlation between $\mathrm{QB} / \mathrm{BC}$ ratio and $\mathrm{PEP} / \mathrm{LVET}$ ratio.

\section{DISCUSSION}

As the maximum pressure of the ITCG is within approximately $2 \mathrm{~mm} \mathrm{H}_{2} \mathrm{O}$, the transducer must have extremely high sensitivity. Although the frequency range of ITCG is, on the other hand, not yet known exactly, the frequency of the spike wave observed in ITCG seems to be about $100 \mathrm{~Hz}$.

In order to record a wave form with a frequency of $100 \mathrm{~Hz}$, it is generally accepted that the maximum frequency of $300 \mathrm{~Hz}$ is necessary for the measuring system. Our transducer has been proved to be suitable for recording ITCG.

Luisada described the pressure changes which occured in the air passages of the lungs as a consequence of the heart beat, and he named this recording as "pneumocardiogram", which was considered as the composition of pressure changes in a closed air cavity associated with both cardiogenic oscillation and pulmonary circulation.

The characteristic points $B$ and $C$ in ITCG which we detected seem to reflect the valvular movements, although we are still uncertain from which side of the heart they arose. The pressure patterns of ITCG are most likely modified by pulmonary circulation also, as can be demonstrated in a pressure change in the reverse direction following the initial contraction pattern (Figs. 2, 3). This 
was favourably demonstrated by the records of ITCG taken pre- and postoperatively from patients with atrial septal defect. The flow pulse in ITCG caused by pulmonary blood flow was diminished after closing the atrial septal defect (Fig. 8). Pulmonary compliance might be another factor influencing the wave form of ITCG. But we have not enough data to discuss about it.

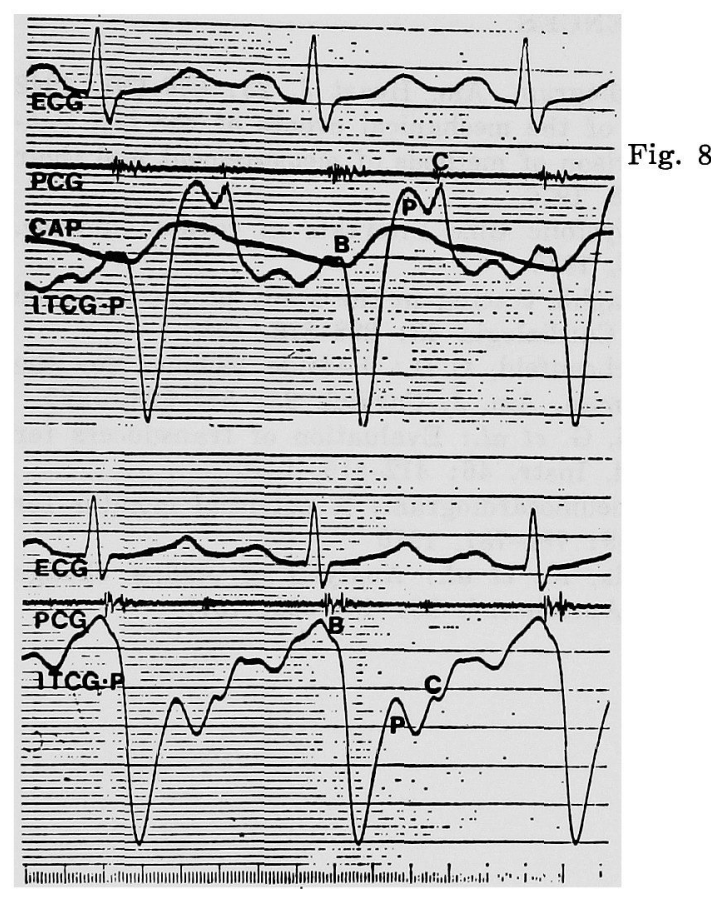

Change in ITCG before (upper section) and after (lower section) closing the atrial septal defect. $P$ in ITCG indicates flow pulse originated from pulmonary blood flow which is diminished after the surgical operation.

Smith and Reitan published that the pneumocardiogram was useful as a clinical tool for monitering heart functions because of the close correlation between acceleration of gas out of the lung and cardiac inotropy.

We have reported elsewhere ${ }^{8}$ the flow change in ITCG by cardiac movement, and it seems to correlate with quantitative changes in cardiac performance. Systolic events obtained by pressure change in ITCG, on the other hand, correlate well with the STI obtained by the ordinary non-invasive technique. The absolute values of each pair of parameters showed essentially the identical values and there was no statistically significant difference among them. These evidences suggest applicability of this technique for evaluating cardiac function. Conventional measurements of STI are sometimes difficult in certain patients especially during surgical operation because of technical problems in recording either the 


\section{PCG or the CAP.}

The measurement of cardiac function by the ITCG can be easily accomplished by recording it simply together with an ECG. This technique is an unique approach for assessing cardiac performance and is non-invasive, provided that endotracheal intubation or tracheostomy is already performed.

\section{REFERENCES}

1. Luisada, A.: The internal pneumocardiogram. Am. Heart J. 23: 676-691, 1942

2. Kumar, S. and Spodick, D. H.: Study of the mechanical events of the left ventricle by atraumatic technique: Comparison of methods of measurement and their significance. Am. Heart J. 80: 401-413, 1970

3. Weissler, A.M. and Garrad, C. L.: Systolic time intervals in cardiac disease. Mod. Concepts Cardiovas Dis. 40: 1-8, 1976

4. Jezek, V.: Clinical value of the polygraphic tracing in the study of the sequence of events during cardiac contraction. Cardiologia 43: 298-316, 1963

5. Weissler, A.M., Harris, W.S. and Schoenfeld, C. D.: Bedside technics for the evaluation of ventricular function in man. Am. J. Cardiol. 23: 577-583, 1969

6. Sekiguchi, H., Shigematsu, T., Kikuchi, G. et al.: Evaluation of transducers for intratracheal cardiogram. J. Jap. Med. Instr. 46: 412-416, 1976

7. Smith, N. T. and Reitan, J. A.: The pneumocardiogram: A potential monitor for the operating room. Anesth. Analg. 49: 781-787, 1970

8. Shigematsu, T., Sekiguchi, H., Yamada, K., et al.: Analysis of airflow change in intratracheal cardiogram. Jap. J. Anesthesiol. 26: 436-441, 1977 